\title{
Suitability of Paulownia Wood from Malaysia for Furniture Application
}

\author{
Hazirah Ab Latib, ${ }^{\mathrm{a}, *}$ Lim Choon Liat, ${ }^{\mathrm{a}}$ Jegatheswaran Ratnasingam, ${ }^{\mathrm{a}, *}$ E. L. Law, ${ }^{\mathrm{b}}$ \\ Amir Affan Abdul Azim, ${ }^{a}$ Manohar Mariapan, ${ }^{\mathrm{a}}$ and J. Natkuncaran ${ }^{\mathrm{c}}$ \\ Imported wood resources, especially yellow poplar and Chinese poplar, \\ are increasingly evident in the Malaysian furniture sector due to declining \\ supply of domestic wood materials. In order to reverse this trend, \\ paulownia, a fast-growing forest plantation tree species, is emerging as \\ an alternative wood material source. This study evaluated the \\ mechanical strength, including fatigue life, machining, adhesive bond, \\ screw withdrawal, and finishing properties of paulownia against the \\ imported wood of yellow poplar and Chinese poplar. The results revealed \\ that paulownia has better properties than Chinese poplar, but it is inferior \\ to yellow poplar due to its lower density. In terms of fatigue strength, all \\ the wood species performed comparably equal, with the allowable design \\ stress set at $40 \%$ of the wood species' respective ultimate bending \\ strength. Against these findings, paulownia is a promising alternative \\ wood resource for furniture manufacturing in Malaysia, and it could \\ possibly replace the imported yellow poplar and Chinese poplar. \\ Nevertheless, the successful application of paulownia for furniture \\ manufacturing will depend on its supply volume and economics in the \\ future.
}

Keywords: Paulownia; Fatigue life; Allowable design stress; Strength; Machining; Finishing; Furniture; Wood

Contact information: a: Universiti Putra Malaysia, Faculty of Forestry, 43400 UPM, Serdang, Selangor, Malaysia, b: Green Afforestation International Network Sdn. Bhd., Level 17, Top Glove Tower, Setia Alam, 40170 Shah Alam, Selangor, Malaysia, c: Faculty of Business, University of Wollongong, NSW 2522, Australia; *Corresponding authors: hazirahablatib@yahoo.com; jegaratnasingam@yahoo.com

\section{INTRODUCTION}

The Malaysian furniture industry has been transformed from a cottage-based industry in the mid-1980s into a multi-billion-dollar export-oriented industry through a series of Industrial Master Plans (IMPs), which have been implemented by the government since 1986. The $1^{\text {st }}$ IMP (1986 to 1995) encouraged down-stream manufacturing, while reducing the export of primary commodities. The $2^{\text {nd }}$ IMP (1996 to 2005) was focused on value-added manufacturing, particularly in the furniture and joinery sectors, while the $3^{\text {rd }}$ IMP (2006 to 2020) was aimed at transforming the industry into a manufacturer of wood products based on innovation and creativity, as well as original brands (MTIB 2019). Against this growth trend, it is no surprise that the Malaysian furniture industry has emerged as an important socioeconomic sector to the country, contributing in excess of USD 2 billion in export earnings annually, while providing employment to nearly 115,000 workers (MTIB 2019). As a large furniture exporting hub, Malaysia exports $85 \%$ of its annual production volume to more than 160 countries throughout the world. The United States of America, Singapore, Australia, 
Japan, South Korea, Europe, South Africa, and the Middle East are among the major export destinations of Malaysian furniture (MTIB 2019). Due to the emergence of regional low-cost furniture producers, especially China and Vietnam, Malaysian furniture manufacturers have come under growing pressure to compete globally, but their resilience has kept them afloat as many of them have embarked on value-added manufacturing to gain the competitive edge (Ratnasingam et al. 2018).

Despite the robust growth of the Malaysian furniture industry, the problem associated with the uncertainty in the supply of raw material remains a challenge (MTIB 2019). The long-term sustainable supply of wood raw material from the natural forests in Malaysia is uncertain due to the reduced logging quota, which allows not more than 4 million $\mathrm{m}^{3}$ of saw logs to be extracted from the natural forests, in line with the Sustainable Forest Management (SFM) practices (FDPM 2018). Furthermore, the reducing acreage of rubber (Hevea brasiliensis) cultivation in the country has adversely affected the supply of rubberwood, the main raw material for the furniture sector. According to the Rubber Industry Smallholders Development Authority (RISDA), due to financial constraints, the annual replanting acreage has been substantially reduced, while interest among smallholders to venture into more profitable crops has increased in recent years (RISDA 2018). This has severely affected the supply of sawn rubberwood in the market. Rubberwood is highly sought after by furniture manufacturers as their main feedstock. Inevitably, the shortage of almost 0.5 million $\mathrm{m}^{3}$ of wood resources faced by furniture manufacturers is overcome by importing wood resources (MTIB 2019).

Yellow poplar (Liriodendron tulipifera) and Chinese poplar (Populus tomentosa) are among the most preferred imported species due to their straight-grained nature, light color, and good working properties. These wood species also dried easily without much generation of defects, but they require preservative treatment to boost their durability (MTIB 2019). Almost 300,000 $\mathrm{m}^{3}$ of these two species of wood were imported into the country in 2018, mostly for furniture manufacturing for the export market. According to the Malaysian Furniture Council (MFC), these imported species are good alternatives to rubberwood (Hevea brasiliensis), which has seen a $20 \%$ spike in price, and the uncertainty in supply continues to put pressure on furniture manufacturers, who are heavily reliant on the export market (MFC 2019). The MFC also reported that with the larger dimensions of lumber available, especially in terms of width and length, these species provide a much higher recovery during processing, and they allow the manufacture of furniture with the need for finger-jointing the shorter length pieces of wood.

To minimize wood imports while ensuring sustainable supply of wood resources, the planting of paulownia, one of the fastest growing tree species in the world, is being aggressively pursued in Malaysia. As a valuable tree for more than 2 centuries, paulownia is indigenous to Northeast Asia, but it has been naturalized to many parts on the world. Several paulownia species are extensively cultivated in China and Japan, and they have shown tremendous growth performance. With annual growth rates of up to 4 $\mathrm{cm}$ per annum under favorable environmental conditions (Koman et al. 2017), cultivation in these countries is successful. Most paulownia species are extremely fast growing and can be harvested in 15 years for valuable timber. When harvested at the age of 5 years, it produces sizable quantities of general utility sawn timber. The paulownia tree at 10 years old can achieve an average diameter at breast height $(\mathrm{DBH})$ of $35 \mathrm{~cm}$, which in turn can produce sawn timber up to $0.5 \mathrm{~m}^{3}$ in volume. With an average density of $300 \mathrm{~kg} / \mathrm{m}^{3}$, the wood of paulownia is soft, whitish color, lightweight, ring-porous, straight-grained, and 
mostly knot-free wood with a satiny luster (Kaygin et al. 2015).

Paulownia wood can be seasoned easily without any major drying defects. With its high strength-to-weight ratio, a low shrinkage coefficient, and a low tendency to warp or crack, the wood has found widespread acceptance in the wood products industry in Northeast Asia. Although it is not durable, its ease of preservative treatment application makes it desirable for wood products manufacturing. In China and Japan, paulownia wood is used for a variety of applications such as plywood, molding, furniture, shipbuilding, packing boxes, and cabinetmaking due to its good machining and finishing properties (Kaygin et al. 2015).

Although paulownia plantations have been established in the Malaysia since the late 1990s, most of the plantations did not yield the desired result (FDPM 2018). In later years, the species Revotropix paulownia was introduced, producing better and sustainable result as plantations, and it has emerged as the most common paulownia clone planted in the country. This clone of paulownia is also known scientifically as Paulownia fortunei. This tree crop produces up to $450 \mathrm{~m}^{3}$ of wood per hectare, as opposed to the rubber plantations, which have an average wood yield of $200 \mathrm{~m}^{3}$ per hectare (FDPM 2018). In 2019 , almost 16,000 hectares of land were used for cultivation of this paulownia species, and by 2025, this figure could reach up to 150,000 hectares (FDPM 2018). To utilize paulownia wood in the furniture industry, information on its strength and working properties are highly desirable (Ratnasingam et al. 1997), but information on these aspects are currently sparse. This is even more important if the paulownia wood replaces the commercially successful imported species of yellow poplar (Liriodendron tulipifera) and Chinese poplar (Populus tomentosa) in furniture manufacturing.

This study evaluated the strength (static and fatigue), machining, adhesive bonding, fastening, and finishing properties of the paulownia wood in comparison to the more established yellow poplar (Liriodendron tulipifera) and Chinese poplar (Populus tomentosa) in order to assess its suitability for furniture.

\section{EXPERIMENTAL}

Revotropix paulownia, yellow poplar, and Chinese poplar ungraded sawn timber samples were obtained from the local supplier. The samples were kept in a conditioning room at $20 \pm 2{ }^{\circ} \mathrm{C}$ temperature and $65 \pm 5 \%$ relative humidity for 6 months to ensure constant weight. The moisture content and density of the samples were determined prior to further testing.

The scope of this study was to provide an overview of the working properties of the paulownia wood, in comparison to the wood species it intends to replace in furniture manufacturing. Generally, the working properties of wood (i.e. mechanical strength, machining, adhesive strength, and fastening strength) determines its success for furniture application.

In this context, the strength properties of the wood species, including modulus of elasticity (MOE), modulus of rupture (MOR), shear, compression perpendicular to the grain, and hardness, were determined in accordance with ASTM D-143 (1994). This standard was used for testing in this study due to the fact that the other two imported wood species, i.e. yellow poplar and Chinese poplar are traded and marketed in the country, based on strength evaluations done according to the ASTM standard.

The machining test was performed in accordance with ASTM D-1666-87 (1993). 
Although in furniture manufacturing, machining operations include planing, shaping, routing, boring, and sanding, in this study the focus was primarily on the planing and shaping processes, which were deemed to be the two most important machining operations in furniture manufacturing (Ratnasingam 2017). The planing test was conducted on a Weinig-22A through-feed molder (Tauberbischofsheim, Germany) with five spindles, but only the top spindle, with a single high-speed steel (HSS) cutter with a rake angle of $15^{\circ}$, was used. The spindle was rotated at 6000 RPM, and the feed rate was maintained so that the pitch distance between cutter marks was $0.8 \mathrm{~mm}$ (or rather 20 cuts per inch). All specimens of a common thickness were run one after another, and the machine height setting was changed to accommodate thinner stock. The resultant surface quality of the machined samples was evaluated both visually and by touch. The ASTM D1666 (1993) standard uses five quality grades based on the amount and severity of defect present. Samples were graded for the presence of fuzzy grain, raised grain, torn grain, chip marks, and cracks. The planing test was followed by a shaping test, carried out using a SCM T80C single-spindle shaper (Rimini, Italy) rotating at 7200 RPM. The shaping test allowed the assessment of curved or profile machining of the samples. A cutter head with 6-winged high-speed steel (HSS) knives with $15^{\circ}$ rake angle was used. The profile of the knives was as specified in the ASTM standard. A jig with a toggle clamp was used to hold the sample. The jig enabled the curved patterns to be replicated for all samples. Surface quality assessment was similar to that of the planing test, using visual and touch assessment.

The shearing strength of an adhesive laminated bond of the wood samples was determined according to ASTM D-905 (1993). In a shear test the true indication of a good bond is when there is wood failure present in the fracture area, which is determined by judging the percentage of the surface area of the joint that manifested fibers torn away from the opposing surface. A $100 \mathrm{kN}$ servo-hydraulic universal testing machine (Instron, Norwood, MA, USA) was used to apply a shear force in compression to the samples of laminated-shearing block using polyvinyl acetate adhesive with a crosslinking agent added (PVAc). The fastener withdrawal test was conducted to determine the force necessary to withdraw a screw type fastener, according to ASTM D-1761-88 (1993). The fastener withdrawal test measured the maximum withdrawal force required to pull two screws from either flat or vertical grain samples (chosen at random). The screws were screwed to a depth until the threads were no longer visible, while allowing the gripper to firmly secure the screw-head. The withdrawal rate was tested at $2.5 \mathrm{~mm} / \mathrm{min}$ on a $100 \mathrm{kN}$ servo-hydraulic universal testing machine.

The finishing properties of the samples were evaluated using the two most common types of finishes used in the furniture industry, i.e., stain/water-based varnish and lacquer primer/lacquer top-coat. The final dry-film thickness of both the base-coat and top-coat were fixed at approximately $120 \mu \mathrm{m}$, measured using a dry-film thickness gauge. The finishes were evaluated for the adhesion of the coating to the substrate and its gloss level according to ASTM D-3359 (1994) and ASTM D-523 (1994), respectively. All samples were sanded using 150 grit aluminum-oxide sandpaper to ensure a smooth surface before finish application. The adhesion test involved the use of 3M-tape that is adhered to a knife hatched-pattern coated surface, which is then pulled off. The resulting surface is examined for removal of coating material from either the substrate or the previous under-coat/primer. The percentage of the hatched area that remained on the tape is calculated by visual examination of the tape by holding it up to the light. Gloss is a measure of the capacity of the surface to reflect more light in one direction than another. 
The gloss test is a comparative test in which samples are tested for their $60^{\circ}$ gloss values and compared to the gloss value of the coating when it is applied to a black glass block. A Schidmt F30 Parallel-Beam glossmeter (Pennsylvania, USA) was used for this purpose.

Fatigue testing of the samples was conducted using a $100 \mathrm{kN}$ servo-hydraulic universal testing machine. The importance of fatigue strength for furniture application was described in Ratnasingam et al. (1997), and it provides very useful insights into the structural rigidity of the material when put in service in the furniture structure. Failure in furniture structures is often due to fatigue failure under successive loadings. Therefore, an examination of the fatigue properties of the wood species is important to ensure reliable service when used in furniture applications (Ratnasingam et al. 1997; Ratnasingam 2017). The fatigue test was conducted using similar test configuration as in Eckelman and Bao (1995), and the specimens were subjected to different stress levels (i.e., 40, 50, 60, 70 , and $80 \%$ ) as a percentage of their respective average ultimate bending strength. Due to its long testing duration, only 10 samples were tested at each stress level for each wood species. During fatigue test the servo-hydraulic system exerted and released non-reversal load at rate of $2 \mathrm{~Hz}$ frequency. Limit switches were used to stop the test when cracks appeared on the specimens. After the fatigue test, $\mathrm{S}-\mathrm{N}$ curves were obtained.

All parameters from this study were subjected to the statistical tests of multiple comparisons and analysis of variance (ANOVA). The significant differences between the mean values of the three wood species for each test were evaluated using the Duncan's multiple range test. All these statistical tests were calculated using the SPSS version 10.1 statistical analysis software (IBM, Armonk, NY, USA), and the significance level was set at $\mathrm{P}<0.05$.

\section{RESULTS AND DISCUSSION}

Table 1 shows comparative strength properties of the paulownia wood against the yellow poplar and Chinese poplar wood. The results were significantly different, where the paulownia wood has strength properties between that of the yellow poplar and Chinese poplar. There was a strong relationship between the density of the material and its strength properties, as established by Desch and Dinwoodie (1996). The strength results of the yellow poplar and Chinese poplar wood found in this study are comparable to those reported previously (Ross 1987; Green and Evans 2003; Ming-Li et al. 2019). The strength properties of the paulownia wood in this study were comparable to the properties of the planted Paulownia tomentosa in Hungary (Koman et al. 2017). The clone Revotropix paulownia appears to be comparable to other plantation-grown paulownia species, and its strength properties demonstrate that it is suitable for furniture application. 
Table 1. Comparative Mechanical Properties of the Wood Species

\begin{tabular}{|l|c|c|c|}
\hline \multicolumn{1}{|c|}{ TEST } & Paulownia & Yellow Poplar & Chinese Poplar \\
\hline $\begin{array}{l}\text { Density at } 12 \% \text { moisture } \\
\text { content }\left(\mathrm{kg} / \mathrm{m}^{3}\right)\end{array}$ & $325(23)$ & $420(23)$ & $285(18)$ \\
\hline Modulus of Elasticity $\left(\mathrm{N} / \mathrm{mm}^{2}\right)$ & $5145(44)$ & $8240(91)$ & $4910(39)$ \\
\hline Modulus of Rupture $\left(\mathrm{N} / \mathrm{mm}^{2}\right)$ & $47.25(3.21)$ & $68.00(5.11)$ & $38.60(2.78)$ \\
\hline $\begin{array}{l}\text { Compression I to grain } \\
\left(\mathrm{N} / \mathrm{mm}^{2}\right)\end{array}$ & $26.48(2.44)$ & $33.40(2.97)$ & $21.60(1.98)$ \\
\hline Shear $\left(\mathrm{N} / \mathrm{mm}^{2}\right)$ & $8.10(0.7)$ & $9.9(0.9)$ & $7.3(0.5)$ \\
\hline Hardness $(\mathrm{N})$ & $1960(81)$ & $2400(101)$ & $1700(66)$ \\
\hline
\end{tabular}

Notes: A total of 20 replicates were used for each test. Figures in parentheses indicate the standard deviation.

Figure 1 shows the planing test results of the three wood species. As reported previously, the pitch distance between the cutter marks in the planing operation was set at $0.8 \mathrm{~mm}$. Using a rake angle of $15^{\circ}$ produced the best machined surface quality for furniture application (Ratnasingam and Tanaka 2002). The best results for planing were produced by yellow poplar, followed by paulownia and Chinese poplar. All paulownia samples manifested fuzzy grain, which was completely removed by sanding. However, if the criteria for the evaluation of paulownia included good to excellent samples (defect free), the average number of samples pieces falling into Grade 1 and Grade 2 category was as high as $90 \%$, clearly highlighting the good planing characteristics of paulownia.

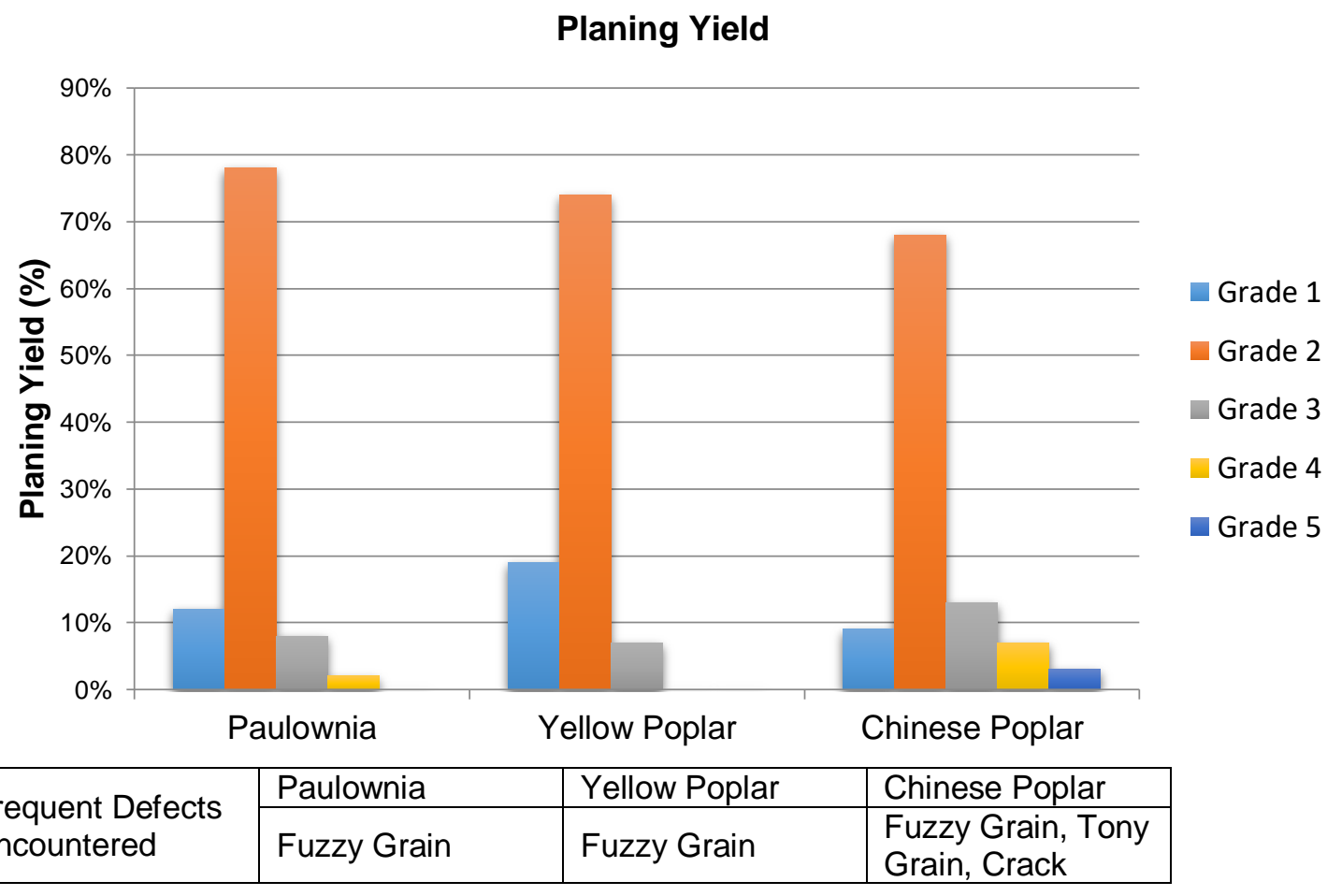

Fig. 1. Comparative planing yield of the wood samples. A total of 20 replicates were used for the machining test

Similar to the planing results, yellow poplar produced the best shaping result, followed by paulownia and Chinese poplar (Fig. 2). In evaluating machining characteristics, there is a link between density and resultant surface finish, and in this study, the results obtained reflect the difference in the densities of the wood 
(Ratnasingam and Tanaka 2002). The results indicated that paulownia is a good species to shape, but it is prone to a higher percentage of fuzzy grain and torn grain surfaces on curved surfaces than yellow poplar, which produced less defects. The percentage of defect-free paulownia wood samples was $19 \%$ compared with $31 \%$ for yellow poplar and $11 \%$ for Chinese poplar.

Table 2 shows the adhesive bond shear strength of the three species. Fortified polyvinyl acetate adhesive cured with radio-frequency heating was used to reflect the common adhesive and method used in the furniture industry. Bandel (1995) reported that a minimum adhesive shear strength value of $14 \mathrm{~N} / \mathrm{mm}^{2}$ is sufficient for most furniture applications. Therefore, it appears that adhesive-jointed paulownia meets the minimum requirement for furniture application under most circumstances. Based on this study, the adhesive bond strength of paulownia, which was in between that of yellow poplar and Chinese poplar, clearly highlights that paulownia is a suitable alternative for the other two imported wood species for furniture application in Malaysia.

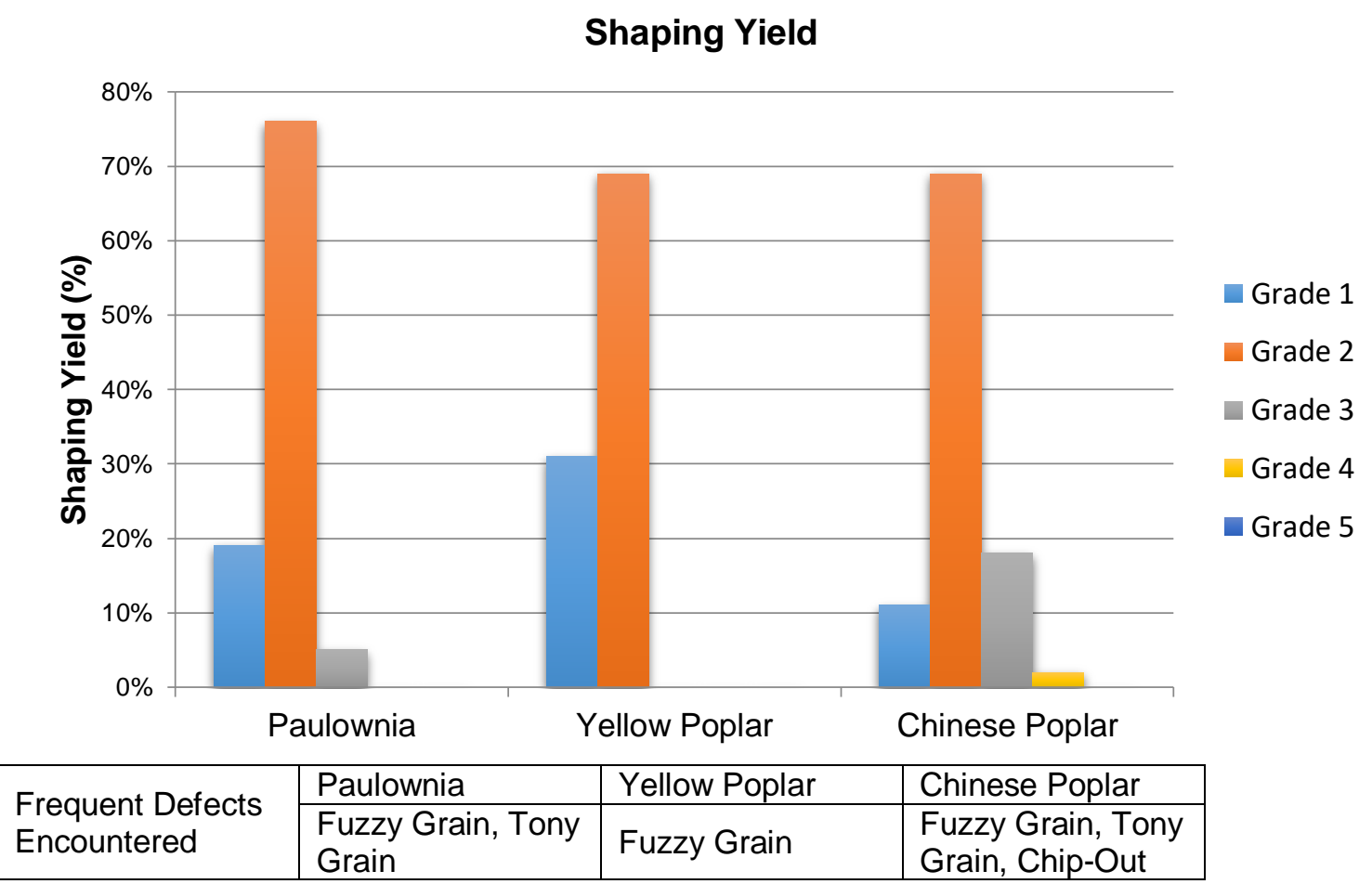

Fig. 2. Comparative shaping yield of the wood samples. A total of 20 replicates were used for the machining test.

Table 2. Comparative Adhesive Shear Strength

\begin{tabular}{|l|c|c|c|}
\hline \multicolumn{1}{|c|}{ TEST } & Paulownia & Yellow Poplar & Chinese Poplar \\
\hline $\begin{array}{l}\text { Adhesive Shear Strength } \\
\left(\mathrm{N} / \mathrm{mm}^{2}\right)\end{array}$ & $16.1(1.3)$ & $18.3(1.8)$ & $14.1(1.1)$ \\
\hline$\%$ average wood failure & $98 \%$ & $100 \%$ & $89 \%$ \\
\hline$\%$ average adhesive failure & $2 \%$ & $0 \%$ & $11 \%$ \\
\hline
\end{tabular}

Notes: A total of 20 replicates were used for each test. Figures in parentheses are standard deviation values. 
The fastener strength of the three wood species is shown in Fig. 3. Yellow poplar performed much better than paulownia, which in turn was better than the Chinese poplar in terms of screw withdrawal strength. The higher density material resulted in higher screw withdrawal strength and vice versa (Desch and Dinwoodie 1996).

The finishing properties of the three wood species are given in Table 3. All coatings performed well with regard to the tape pull-off test, with all the three wood species showing excellent coating film adhesion, with no inter-coating failures. The good adhesion results obtained from this study suggest that the finishing properties of paulownia are comparable to those of the other two species.

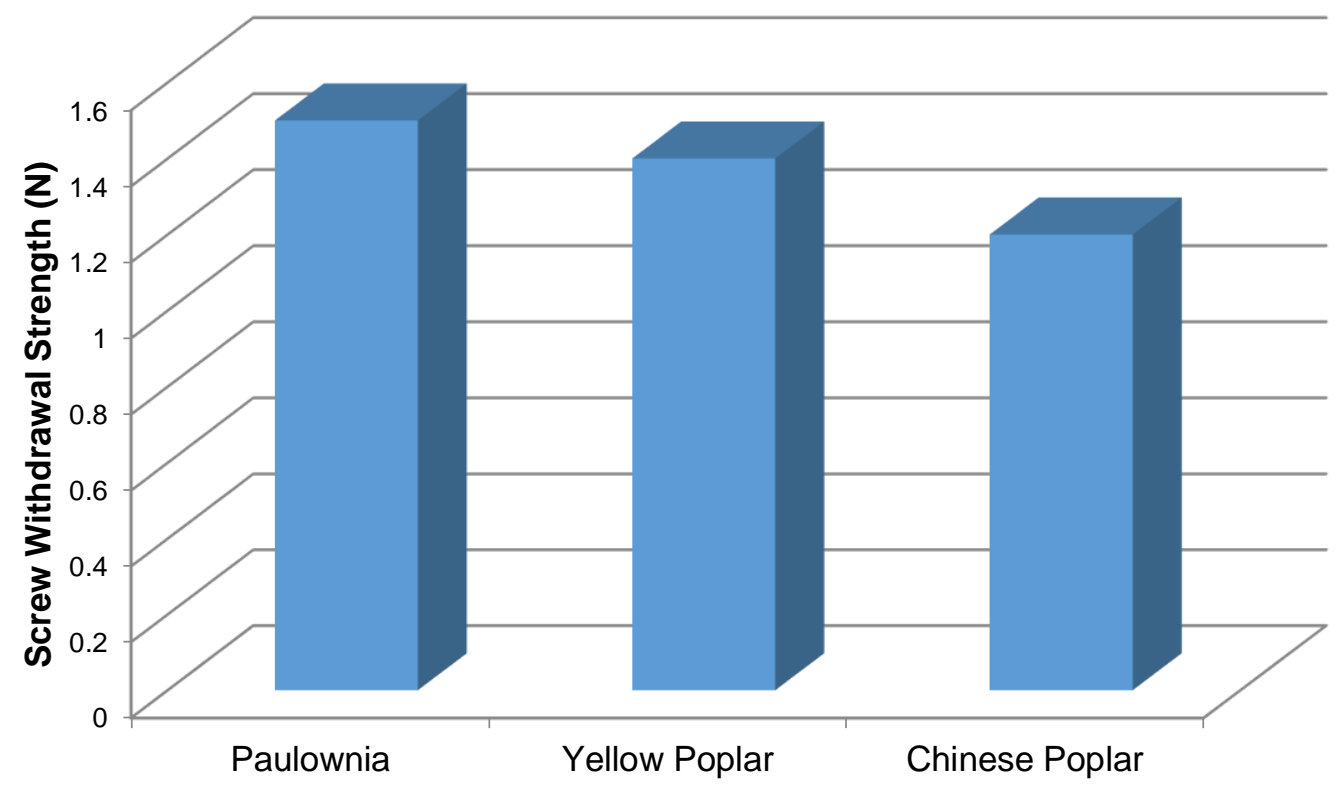

Fig. 3. Comparative fastener withdrawal strength. A total of 20 replicates were used for each test.

Table 3. Finishing Properties of the Wood Samples

\begin{tabular}{|l|c|c|c|c|}
\hline \multicolumn{1}{|c|}{ Test } & $\begin{array}{c}\text { Finish } \\
\text { Type }\end{array}$ & Paulownia & Yellow Poplar & Chinese Poplar \\
\hline $\begin{array}{l}\text { Coating } \\
\text { Adhesion }\end{array}$ & Type-1 & $100 \%$ & $100 \%$ & $100 \%$ \\
\cline { 2 - 5 } Strength & Type-2 & $100 \%$ & $100 \%$ & $100 \%$ \\
\hline $\begin{array}{l}\text { Average Tape } \\
\text { Pull-Off Force } \\
\left(\mathrm{N} / \mathrm{mm}^{2}\right)\end{array}$ & Type-1 & $2.19(0.03)$ & $2.38(0.01)$ & $2.01(0.03)$ \\
\cline { 2 - 5 } $\begin{array}{l}60^{\circ} \text { Gloss on } \\
\begin{array}{l}\text { Finished } \\
\text { Wood } \\
\text { Substrate }\end{array}\end{array}$ & Type-2 & $1.72(0.02)$ & $1.87(0.01)$ & $1.69(0.02)$ \\
\cline { 2 - 5 } & Type-2 & 63 & 78 & 69 \\
\hline
\end{tabular}

Notes: A total of 20 replicates were used for each test. Figures in parentheses are standard deviation values. Type 1 refers to the varnish finish, while Type 2 is the lacquer finish. The gloss reading is compared to the standard $60^{\circ}$ gloss on a black glass surface coated with the two different finishes, which gave the results 80 and 90, respectively. 
However, the gloss performance of the yellow poplar was much better than the paulownia and Chinese poplar. Nevertheless, there was no significant difference between the gloss levels of the latter two wood species. The variance in gloss level between the standard and the wood test pieces is a good indicator of gloss holdout or porosity of the substrate. Hence, paulownia may necessarily require a higher volume solid coatings or more layers of the coating to improve its gloss level compared with yellow poplar, which recorded higher level of gloss due to its higher density and close texture (Flexner 1994). Although all of the species have similar straight grains, the differences in the texture have a strong influence on the porosity, which in turn explains the need for several layers of coating in order to achieve a smooth and flat finish (Ross 1987).

Figure 4 shows the S-N scatter plots for the fatigue life of the paulownia, yellow poplar, and Chinese poplar samples. The inverse relationship between fatigue life and applied stress level for the specimens revealed a linear trend. The results suggest that at a stress level of $40 \%$ of the average MOR, all specimens survived a million test cycles. However, at a stress level of $50 \%$ of its MOR, all specimens did not survive the million cycles in fatigue life, but the samples showed different levels of resilience. The reduction in fatigue strength in paulownia was slower than in Chinese poplar but was more pronounced with abrupt failures than yellow poplar, which manifested cracks before the specimens failed. The results also reinforced that the fatigue strength of wood reduces as the applied stress levels increases (Ratnasingam et al. 1997). Thus, the allowable design stress for the paulownia wood in furniture applications should not exceed $40 \%$ of its ultimate bending strength of modulus of rupture. This result confirms previous reports on fatigue strength by Eckelman and Bao (1995) and Ratnasingam and Ioras (2010).

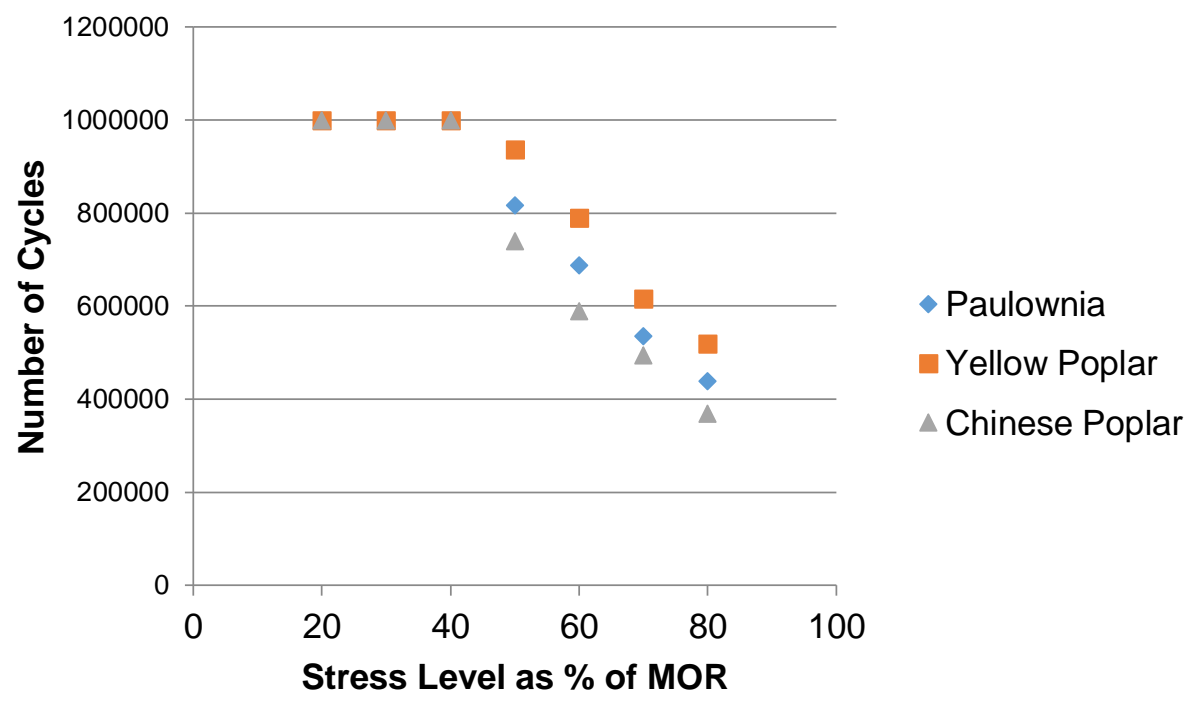

Fig. 4. Comparative fatigue life of the different wood species

\section{Implications of This Study}

This study showed that the clone Revotropix paulownia produces wood that has competing qualities with the current imported yellow poplar and Chinese poplar. In this context, this study provides compelling evidence that with comparable strength characteristics as well as its light color, the paulownia wood may be suitable for furniture applications. This may ease some off the pressures faced by furniture manufacturers, who 
are desperately looking at domestic wood resources to replace the imported wood resources, which at times are expensive, due to the exchange-rate fluctuations. Unlike the previously failed paulownia cultivation in the country (FDPM 2018), this clone of paulownia is more promising and is suitable as an alternative raw material for the furniture manufacturing industry. With its fast growing rate and sustainability, paulownia wood may emerge as a viable replacement for imported wood resources. Despite its favorable strength, machining, adhesive bonding, fastener withdrawal, and finishing properties, the future success of paulownia wood as an important furniture manufacturing raw material in Malaysia depends on its supply volume and production economics.

\section{CONCLUSIONS}

1. Paulownia wood showed better performance than Chinese poplar, in terms of the strength, machining, adhesive bond, fastener withdrawal, and finishing properties. Because of its lower density, its performance in comparison to yellow poplar was inferior.

2. In terms of fatigue strength, paulownia wood showed similar fatigue life compared to the other two wood species, and the allowable design stress for the wood in furniture applications must be set at $40 \%$ of its ultimate bending strength.

3. On account of its light color, good strength and working properties, paulownia wood is a suitable replacement for imported yellow poplar and Chinese poplar in furniture manufacturing.

4. Although paulownia appears suitable as an alternative raw material for furniture manufacturing on the basis of its acceptable strength characteristics, its long-term success will still depend on sustainable supply as well the economics.

\section{ACKNOWLEDGEMENTS}

The authors are grateful for the financial support from Universiti Putra Malaysia under the PUTRA Grant No. 9649900, for the procurement of the wood samples. The assistance of Dr. Manohar Mariapan with the statistical analysis in this study is also appreciated.

\section{REFERENCES}

ASTM D 143-83 (1994). "Standard methods of testing small clear specimens of timber," ASTM International, West Conshohocken, USA.

ASTM D 1666-87 (1993). "Standard methods for conducting machining tests of wood and wood-based materials," ASTM International, West Conshohocken, USA.

ASTM D 1761-88: (1993). "Standard test method for mechanical fasteners in wood," ASTM International, West Conshohocken, USA.

ASTM D 3359-93 (1994). "Standard test methods for measuring adhesion by tape test," ASTM International, West Conshohocken, USA.

ASTM D 523-89 (1994). "Standard test method for specular gloss," ASTM International, 
West Conshohocken, USA.

ASTM D 905-89 (1993). "Standard test method for strength properties of adhesive bonds," ASTM International, West Conshohocken, USA

Bandel, A. (1995). Gluing Wood for Furniture Application, CATAS Publication, Milan, Italy.

Desch, H. E., and Dinwoodie, J. M. (1996). Timber: Its Structure, Properties, Conversion and Use, Macmillan Press, London.

Eckelman, C. A, and Bao, Z. Z. (1995). "Fatigue life and design stress for wood composites used in furniture," Forest Product Journal 45(7/8), 59-63.

FDPM (2018). Forest Plantation Development in Peninsular Malaysia, Report No. 71FP. Forest Department of Peninsular Malaysia, Kuala Lumpur, Malaysia.

Flexner, B. (1994). Understanding Wood Finishing, Rodale Press, Emmaus, Pennsylvania.

Green, W. D., and Evans, J. W. (2003). "Effects of low relative humidity on properties of structural lumber products," Wood and Fiber Science 35(2), 247-265.

Kaygin, B., Kaplan, D., and Aydemir, D. (2015). "Paulownia tree as an alternative raw material for pencil manufacturing," BioResources 10(2), 3426-3433. DOI: 10.15376/biores. 10.2.3426-3433

Koman, S., Feher, S., and Vityi, A. (2017). "Physical and mechanical properties of Paulownia tomentosa wood planted in Hungary," Wood Research 62(2), 335-340.

Malaysian Furniture Council (MFC) (2019). Trends in Wood Resources Demand and Supply for Furniture Industry, Newsletter No. 4, pp. 8-10. Kuala Lumpur, Malaysia.

Malaysian Timber Industry Board (MTIB) (2019). Annual Report of the Malaysian Wood Industry, Kuala Lumpur, Malaysia.

Ming-Li, L., Chun-Feng, L., and Yan-Long, L. (2019). "Physical and mechanical properties of modified poplar wood by heat treatment and impregnation of sodium silicate solution," Wood Research 64(1), 145-154.

Ratnasingam (2017). The Malaysian Furniture Industry: Charting Its Growth Potential. Inaugural Lecture Monograph No. 216, Universiti Putra Malaysia Press, Serdang, Malaysia.

Ratnasingam, J., and Tanaka, C. (2002). Wood Machining Processes: A Managerial Perspective, Tanabe Foundation Publication, Shimane, Japan.

Ratnasingam, J., and Ioras, F. (2010). "Static and fatigue strength of oil palm wood used in furniture," Journal of Applied Sciences 10(11), 986-990. DOI: 10.3923/jas.2010.986.990

Ratnasingam, J., Chin, K. A., Abdul Latib, H., Subramaniam, H., and Khoo, A. (2018). "Innovation in the Malaysian furniture industry: Drivers and challenges," BioResources 13(3), 5254-5270. DOI: 10.15376/biores.13.3.5254-5270

Ratnasingam, J., Perkins, M., and Reid, H. (1997). "Fatigue: It's relevance to furniture," Holz als Roh- und Werkstoff 55(5), 297-300.

RISDA (2018). Annual Report on the Rubber Sector in Malaysia, Rubber Industry Smallholders Development Authority, Kuala Lumpur, Malaysia.

Ross, R. J. (1987). The Encyclopedia of Wood, Sterling Publishing Inc., New York.

Article submitted: April 8, 2020; Peer review completed: April 26, 2020; Revised version received and accepted: April 29, 2020; Published: May 5, 2020.

DOI: 10.15376/biores. 15.3.4727-4737 